\title{
An immune challenge of female great tits decreases offspring survival and has sex-specific effects on offspring body size
}

\author{
Justyna Kubacka ${ }^{1,2}$ (D) Mariusz Cichon ${ }^{1}$ (D) \\ Received: 24 November 2019 / Revised: 24 August 2020 / Accepted: 4 September 2020 / Published online: 12 September 2020 \\ (C) The Author(s) 2020
}

\begin{abstract}
Investment in immunity is expected to decrease (costly immunity) or enhance (terminal investment) reproductive performance. Here, we tested the effects of activation of the immune system in female great tits (Parus major) on (1) their reproductive effort and (2) the survival and body condition of their offspring, controlling for chick sex. We injected females tending 3-day-old chicks with sheep red blood cells (SRBC) or saline (control) and recorded their provisioning rates 6 days later, during the expected peak of antibody production. We measured tarsus length and body mass in 11-day-old chicks and monitored changes in brood size. We found that female provisioning rates were unaffected by the SRBC challenge. An analysis without an outlier, however, showed a significant challenge-by-hatch date interaction. This interaction indicated that female provisioning rates decreased with hatch dates in the SRBC but not in the control nests, suggesting a stronger effect in later breeders. Chick body mass was not affected by female immunisation nor by its interaction with chick sex. However, we found a significant challenge-by-sex interaction on offspring tarsus. In SRBC nests, the difference in tarsus length between male and female chicks was lower than in controls, suggesting sex-dependent effects of the challenge on offspring structural growth. Finally, chick mortality was greater in SRBC nests compared with controls, but chick survival probability was not affected by sex. Overall, our results support the costly immunity but not the terminal investment hypothesis in the great tit.
\end{abstract}

Keywords Life history $\cdot$ Reproduction and immunity trade-off $\cdot$ Birds $\cdot$ Immune challenge $\cdot$ Non-pathogenic antigen $\cdot$ Sex-specific effect

\section{Introduction}

Mechanisms underlying life history decisions can be better understood by studying their relationship with immune function, which, being part of self-maintenance, is expected to be traded-off with reproduction (Stearns 1992; Zuk and Stoehr 2002). This generates two complementary predictions, assuming that resources are limited (Norris and Evans 2000). First,

Electronic supplementary material The online version of this article (https://doi.org/10.1007/s10211-020-00351-w) contains supplementary material, which is available to authorized users.

Justyna Kubacka

jkubacka@miiz.waw.pl

1 Institute of Environmental Sciences, Faculty of Biology, Jagiellonian University, Gronostajowa 7, 30-387 Kraków, Poland

2 Museum and Institute of Zoology, Polish Academy of Sciences, Wilcza 64, 00-679 Warszawa, Poland investment in reproduction can impair performance of the immune system. Second, individuals mounting an immune response are predicted to decrease their breeding effort and may suffer a lower current reproductive success.

In birds, the former prediction has been widely tested experimentally, showing that increased breeding effort negatively affects immune function and parasite load (Knowles et al. 2009; González-Medina et al. 2015; Colominas-Ciuró et al. 2017). In contrast, effects of immune responses on reproductive effort and success have received less attention, and the studies yielded mixed results. These effects have typically been tested experimentally, by activation of the immune response with a novel, non-pathogenic antigen (immune challenge), such as sheep red blood cells (SRBC), lipopolysaccharide (LPS), Newcastle disease virus (NDV) or tetanus toxoid (Demas et al. 2011). Injecting a non-pathogenic antigen triggers the immune response but does not involve toxicity to cells. Thus, a non-pathogenic antigen allows studying the costs of the immune response independently of the negative effects caused by multiplication of a pathogenic microorganism. 
Some of the avian studies that employed immune challenge showed its negative influence on clutch initiation date, egg size, brood size, brood feeding rates, chick quality, reproductive success and time to relay a replacement clutch (Ilmonen et al. 2000; Råberg et al. 2000; Bonneaud et al. 2003; Marzal et al. 2007; Gasparini et al. 2009; Cucco et al. 2010; Needham et al. 2017). These results lend support for the costly immunity hypothesis, stating that costs of mounting an immune response are negatively reflected in current reproduction. However, other studies failed to find a negative effect of immune system activation on variables related to reproductive effort and output (Williams et al. 1999; Råberg et al. 2000; Bonneaud et al. 2003, 2004; Marzal et al. 2007) or found negative effects that were dependent on parental age, sex of young or environmental conditions (Lozano and Ydenberg 2002; Bonneaud et al. 2004; Hanssen 2006; Velando et al. 2006; Bowers et al. 2012; Grzeedzicka 2017). Thus, the costly immunity hypothesis has to date not found conclusive support.

In fact, in some studies, the effect of immunisation increased breeding effort and performance. Activation of the immune response can decrease survival and longevity (Hanssen et al. 2004; Eraud et al. 2009) and thus can be interpreted by an individual as a cue of lowered chances of future survival and consequently a lowered residual reproductive value. As a result, an individual which otherwise would save resources for future reproduction will enhance its current reproductive effort. Yet, this terminal investment hypothesis (Clutton-Brock 1984) has received limited interest in avian studies that experimentally manipulated the immune response to determine its effect on breeding performance (Lozano and Ydenberg 2002; Bonneaud et al. 2004; Hanssen 2006; Velando et al. 2006; Bowers et al. 2012; Sköld-Chiriac et al. 2019).

Here, we investigated whether immunisation of free-living female great tits (Parus major) with SRBC affects their reproductive effort (provisioning rates) and output (offspring body mass, body size and survival). According to the costly immunity hypothesis, an immune challenge would negatively affect reproductive effort and performance, while it would increase breeding effort and output under the terminal investment hypothesis. We also tested whether the immunisation effects on offspring are sex-dependent. In the great tit, this can be expected because males are larger than females (Svensson 1992) and therefore more costly to produce, which suggests that parental condition might have different effects on male and female chicks (Trivers and Willard 1973; Nager et al. 1999).

\section{Methods}

\section{Study area and general protocol}

The study was conducted during one breeding season in the Niepołomice Forest, southern Poland (N 50 $6^{\prime}$, E $20^{\circ} 25^{\prime}$ ), in a population of great tits breeding in nest boxes. To estimate clutch sizes and hatching dates, after April 20, we carried out regular nest box checks. We determined the first egg-laying date by subtracting the number of eggs found before clutch completion from the date of the check, assuming that only one egg is laid per day. To find out the final clutch size, we checked the box 15 days after the first egg date. The expected hatching date was then calculated as the final clutch date plus 11 days. Beginning from the expected hatching date, we conducted checks every day, to pinpoint the date of hatching (day 0 ). Days after hatching are given as ' + ' followed by the number of days since the hatching date.

The study was carried out on 23 nests during the first breeding attempt. The order of procedures was as follows (see below for detailed description). On day +3 , we caught and ringed the female or both parents at each nest and carried out the immune challenge procedure on the females. Chicks were blood sampled for sex identification. On day +9 , we videotaped nest boxes to record female brood provisioning rates. On day +11 , the body mass and tarsus of chicks were measured. Brood size was tracked throughout chick development $(+3,+9,+11,+14)$. Between +11 and +14 , a second capture attempt was made to catch and ring the male if he had not been caught on +3 .

\section{Immunisation of females}

Females were metal-ringed and given an individual combination of three colour plastic rings (AC Hughes, UK). Males, if caught, were metal-ringed. Each nest was randomly assigned to the experimental or control treatment. Females tending experimental nests $(N=12)$ were injected intraperitoneally with $0.1 \mathrm{ml}$ of $40 \%$ SRBC solution in phosphate-buffered saline (PBS), and those tending control nests $(N=11)$ were injected with $0.1 \mathrm{ml}$ PBS. Birds were released immediately after injection.

SRBC has been widely used in eco-immunology studies to evaluate the costs of the immune response on reproduction and survival in captive and wild birds (Williams et al. 1999; Lozano and Ydenberg 2002; Verhulst et al. 2005; Hanssen 2006; Pinxten et al. 2008; Demas et al. 2011; Martyka et al. 2011; Rutkowska et al. 2012). This non-pathogenic antigen triggers a humoral immune response by activating B lymphocytes with the help of T lymphocytes, ultimately leading to the production of antibodies by the former (Janeway et al. 2001). SRBC is a relatively benign antigen, which does not cause multiple effects, unlike, e.g. LPS (Hõrak et al. 2003; Davison et al. 2008). In birds, the antibody response to SRBC elevates the basal metabolic rate and reduces locomotory activity (Ots et al. 2001; Hõrak et al. 2003; Eraud et al. 2005). It can also be an index of resistance to natural pathogens. For example, lines of poultry selected for high antiSRBC antibody production show higher resistance, relative 
to lines selected for none or low SRBC response, to important avian pathogens, such as the Newcastle disease virus, Mycoplasma gallisepticum, Eimeria necatrix, a splenomegaly virus and feather mites (Gross et al. 1980).

\section{Recording brood provisioning rates}

Parental feeding rates were videotaped with digital cameras (Samsung and Sony) mounted on plastic holders screwed to trees (ca. 3-7 $\mathrm{m}$ from nest box). The day of videotaping (+9) corresponded to the expected peak of antibody production in the great tit following immunisation with SRBC (Snoeijs et al. 2007) and high brood demand (van Balen 1973). Each nest was videotaped for $1 \mathrm{~h}$, between 7 and $11 \mathrm{~h}$ a.m. All videos were recorded in rainless weather.

During analysis of the videos, we identified the female by the colour rings and counted the number of feeding events (such that the female entered the nest box with a food item and left it without food). To determine the provisioning rate, we discarded the time preceding arrival of the first parent to feed young (mean \pm standard deviation, $12.6 \pm 11.1 \mathrm{~min}$ ), to eliminate a potential effect of human disturbance on the birds. The provisioning rate was calculated as the number of feeds per hour and per chick.

We observed that at four nests (two SRBC and two control ones) males were not present on the video. In three of these nests, we had either caught the male on day +3 or re-caught him between +11 and +14 . In the case of the fourth nest, however, we did not catch or see the male on day +3 nor during the subsequent trapping attempt.

\section{Measurement of nestling body condition}

In seven control and nine SRBC nests (not all due to manpower limitations), we measured all the chicks when the brood size was up to six and six chicks (two lightest, two middle and two heaviest of the brood) when the brood size was above six. The average proportion of the brood that was measured was $0.65 \pm 0.19$ standard deviation. Tarsus length was measured with a calliper to the nearest $0.1 \mathrm{~mm}$, and body mass was taken with an electronic balance to the nearest $0.1 \mathrm{~g}$. We recorded offspring body mass and body size because they are predictors of survival, recruitment to the breeding population and reproductive investment (Both et al. 1999; Lindström 1999; Monrós et al. 2002; Ringsby et al. 2007; Cleasby et al. 2010), thus being important fitness-related variables.

\section{Offspring sex identification}

Approximately $20 \mu \mathrm{l}$ of blood was collected into a capillary from the pedal vein by puncture with a sterile syringe needle. Blood samples were immediately stored in $96 \%$ ethanol (Sigma-Aldrich). DNA was extracted from blood samples in the Chelex medium (Walsh et al. 1991). Sex was determined by PCR amplification of sequences in the CHD-W and CHD$\mathrm{Z}$ genes, located on sex chromosomes, using the P2 and P8 primers (Griffiths et al. 1998). PCR products were separated by electrophoresis for $60 \mathrm{~min}$ at $80 \mathrm{~V}$, in a $3 \%$ agarose gel stained with ethidium bromide. Sex of the chicks was determined by the presence of the CHD- $Z$ sequence (350 bases, both sexes) and the CHD-W sequence (400 bases, females only).

\section{Statistical analysis}

A general linear model (GLM) was applied to test for the effect of the SRBC challenge on female per capita provisioning rates. We also controlled for the hatch date (May $1=$ day 1 ), because it is associated with temporal changes in environmental conditions and individual quality (Verhulst et al. 1995) and therefore can interact with the effects of immune challenge (Ilmonen et al. 1999; Wiehn et al. 1999; Ardia 2005). Hence, the model included treatment as a fixed effect (SRBC vs. control), hatch date as a covariate and the interaction between the treatment and the hatch date. The hatch date was centred to allow correct estimation and interpretation of the treatment effect in the presence of an interaction (Schielzeth 2010).

We also tested whether there were differences between the SRBC and the control group in variables which could potentially confound the observed effect of immune challenge on the provisioning rates. We fitted one GLM per each variable. We did not find significant differences between treatments in (estimates \pm standard errors are given): hatch date (control $\left.7.27 \pm 0.61, \operatorname{SRBC} 7.00 \pm 0.58, F_{(1,21)}=0.10, p=0.750\right)$, clutch size (control 10.64 \pm 0.59, SRBC 10.42 \pm 0.56 , $F_{(1,21)}=0.07, p=0.789$ ), brood size on day +3 (control $\left.9.64 \pm 0.77, \mathrm{SRBC} 9.42 \pm 0.73, F_{(1,21)}=0.04, p=0.838\right)$, sex ratio in brood on day +3 (proportion of males: control $0.53 \pm 0.06$, SRBC $\left.0.58 \pm 0.05, F_{(1,20)}=0.35, p=0.559\right)$, female body mass on day +3 (control $18.42 \pm 0.21$, SRBC $\left.18.44 \pm 0.21, F_{(1,21)}=0.01, p=0.938\right)$ and time (in minutes) before the arrival of the first parent to feed young (control $\left.15.73 \pm 3.31, \mathrm{SRBC} 9.75 \pm 3.17, F_{(1,21)}=1.70, p=0.206\right)$.

General linear mixed models (GLMMs) were used to test for the effect of immunisation on nestling condition: body mass and tarsus length on day +11 , with 'box ID' as a random factor. We included sex as an explanatory variable and its interaction with treatment, to check whether nestlings of different sex responded differently to the immunisation of the female parents. The non-parametric Wilcoxon rank sum test was applied to test the effect of female SRBC challenge on the change in nestling number between day +3 and +14 . We used a non-parametric test because the change in brood size did not meet the normality assumption. Finally, a general non-linear mixed model with the binomial distribution and logit link was 
applied to test whether the probability of survival to day +14 was affected by treatment, sex and their interaction.

We ran graphical diagnostics of the GLM and GLMM models to make sure that their assumptions (linearity, normality of error and homogeneity of variance) are not violated and checked for outliers using the Cook's distance $(D)$. By eye inspection, we did not identify important departures from model assumptions except for the provisioning model, in which we noticed a clearly influential outlier. This data point had an abnormally high residual, which departed from the normal Q-Q curve and had a $D$ of 1.55 , with the $D$ of the remaining data points being below 0.5 . The outlier was the nest in which the male was not seen on the video nor captured in either of the two trapping attempts. This suggested that the nest could have been tended only by the female and hence could belong to a different statistical population. For this reason, we removed the outlier and re-ran the model. In the model without the outlier, the diagnostics plots did not raise our concerns, and the Cook's distances were all below 0.9. We reported results of the model both with and without the outlier. In addition, we also ran a model that excluded all the four nests to which males did not come to feed during videotaping.

All the computations were performed in the R environment (R Core Team 2019), using the following functions: 'lm' for the general linear models, 'Imer' for the general linear mixed models from the lme4 package (Bates et al. 2015), 'wilcox.test' for the Wilcoxon sum rank test, 'plot_model' for model diagnostics from the 'sjPlot' package (Lüdecke 2020) and 'cooks.distance' to calculate the Cook's distance. Sum contrasts were used in the GLMs and GLMMs, to obtain between-group comparisons for each main effect. To obtain F-statistics for the models, we used the 'Anova' function from the 'car' package (Fox and Weisberg 2011). Throughout Results, we report model estimates \pm standard errors of the dependent variables for the SRBC and control group.

\section{Results}

\section{Female provisioning frequency}

The female provisioning rate was not significantly affected by the immune challenge (control $1.05 \pm 0.18$, SRBC $0.97 \pm$ 0.18 ) nor by its interaction with the hatch date (Table 1 , Fig. 1). However, the model without the outlier showed that while female brood feeding rates were not affected by the SRBC treatment (control $1.06 \pm 0.12$, SRBC $0.77 \pm 0.12$ ), there was a significant treatment-by-hatch date interaction (see Online Resource 1A). When we explored this interaction by testing whether the female provisioning rate varies with the hatch date in each of the two treatment groups separately, we found that it was unrelated to hatch dates in control broods $\left(F_{(1,9)}=0.43, p=0.529\right)$ but decreased with hatch dates in
SRBC broods $\left(F_{(1,9)}=37.25, p<0.001\right.$; see Online Resource 2A).

When we ran the models excluding all the four nests at which the males were not seen during videotaping, the effect of SRBC challenge on female provisioning rate was significant (control $1.19 \pm 0.11$, SRBC $0.72 \pm 0.11$ ) and so was the interaction between the SRBC challenge and hatch dates (see Online Resource 1B and 2B).

\section{Nestling body condition and survival}

Immunisation of female parents did not affect nestling body mass (control $14.93 \pm 0.37$, SRBC $14.98 \pm 0.31$ ) and tarsus length (control 19.45 $\pm 0.20, \mathrm{SRBC} 19.45 \pm 0.16$; Table 2). The interaction between SRBC immune challenge and sex did not affect chick body mass. However, it had a significant effect on tarsus length (Table 2). In SRBC broods, the difference in tarsus length between female and male chicks was smaller compared with control broods (Fig. 2).

The change in brood size between days +3 and +14 was significantly higher in the SRBC-immunised than in the control group (Wilcoxon rank sum test, $W=104.5, p=0.003$ ). All nestlings survived in the nests of control females and mortality (median -1 ; range 0 to -1 ) was observed in seven out of the 12 SRBC nests, with one chick dying by day +9 in each of these nests and no mortality afterwards. Due to the lack of mortality in the control group, we analysed sex effects on chick survival probability only in the SRBC group. In this group, the chances that a chick survives from day +3 to + 14 did not vary between the sexes $(z=1.53, p=0.126)$.

\section{Discussion}

We found that immunisation of breeding female great tits did not affect their provisioning rates. The analysis excluding the outlier nest suggested that SRBC challenge had a hatch datedependent effect on female provisioning rates. In addition, the SRBC challenge had a sex-dependent effect on offspring tarsus length and increased offspring mortality, independently of sex.

Table 1 Results of the GLM testing for the effect of SRBC immunisation of female great tits on their brood provisioning rates, measured as the number of nest visits with prey per hour divided by the brood size (i.e. per chick)

\begin{tabular}{lrrr}
\hline Term & \multicolumn{1}{l}{$F(\mathrm{df})$} & \multicolumn{1}{l}{ Estimate (SE) } \\
\hline Intercept & $63.71(1,19)$ & $<0.001$ & $1.010(0.127)$ \\
SRBC treatment & $0.10(1,19)$ & 0.754 & $0.040(0.127)$ \\
Hatch date & $1.81(1,19)$ & 0.195 & $-0.090(0.067)$ \\
SRBC treatment x hatch date & $0.51(1,19)$ & 0.483 & $0.048(0.067)$ \\
\hline
\end{tabular}

The sum contrasts were applied. $d f$ degrees of freedom, $S E$ standard error 
Fig. 1 Chick provisioning rates (day +9 post-hatch) of female great tits in the SRBC-challenged and control (PBS-injected) group in relation to the hatch date.

Regression lines and their confidence intervals estimated from the female provisioning model (see Table 1) are shown. The arrow indicates the outlier nest

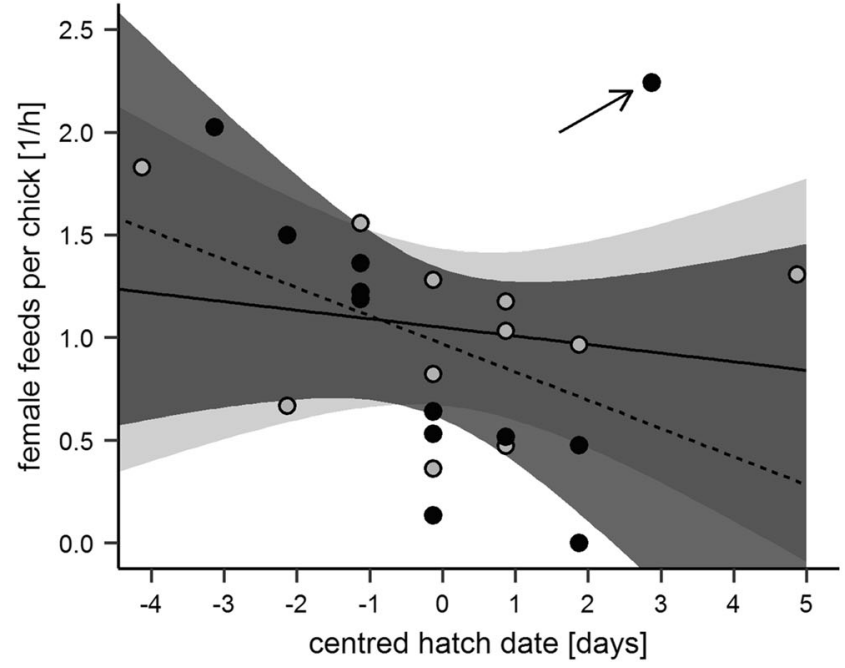

\section{Effects of SRBC challenge on female provisioning rates}

A negative effect of experimental activation of the immune system on chick provisioning rates has been found in female blue tits (Cyanistes caeruleus) immunised with the diphtheriatetanus toxin (Råberg et al. 2000) and in female house sparrows (Passer domesticus) injected with LPS (Bonneaud et al. 2003). Another study actually recorded an increase in feeding rates in SRBC-challenged female great tits (Grzędzicka 2018).

In our study, we did not observe a general effect of SRBC challenge on female provisioning rates. Although we did not measure whether the birds produced antibodies in response to SRBC, this antigen is known to trigger the immune response in the great tit (Ots et al. 2001; Snoeijs et al. 2004a,b, 2007; Pinxten et al. 2008). However, the 1-h videotaping time could have been too short to measure provisioning rates in a representative way. Since all the nest boxes were treated equally (i.e. all of them were recorded for about $1 \mathrm{~h}$ ) and the absence of males during recording was balanced between the treatment groups, these shortcomings should not have caused a bias in provisioning rates in any of the groups. Nevertheless, most likely due to a short recording time, we did not capture some males on the video, and the female provisioning rates in the absence of the males could have been distorted. This is suggested by the provisioning model without the nest boxes at which the males were absent on the video, in which we found a significant effect of the SRBC treatment.

In the model that excluded the outlier nest, we observed an interaction between the immune challenge and hatch dates, suggesting that the negative SRBC effect increased with the time of clutch initiation. In the great tit, as in many other birds, reproductive output declines with hatch dates (Perrins 1970; Perrins and McCleery 1989; Verhulst and Tinbergen 1991; Barba et al. 1995; Verhulst et al. 1995). This pattern is caused by environmental conditions (e.g. food abundance) deteriorating with season advancement, or by parental quality, with higher quality individuals breeding earlier and occupying better territories, or having better foraging abilities compared to late breeders (Verhulst et al. 1995). Consequently, the hatch date-dependent effect of SRBC suggests that in female great tits, the trade-off between offspring provisioning and immunity could be more evident in harsher environmental conditions or lower quality individuals. However, the interaction of hatch dates and female feeding rates must be interpreted with caution, since we cannot be confident that the excluded outlier

Table 2 Results of the GLMMs testing for the effect of SRBC immunisation of female great tits on the body mass and tarsus length of their nestlings at day +11 post-hatch

\begin{tabular}{|c|c|c|c|c|c|c|}
\hline \multirow[t]{2}{*}{ Term } & \multicolumn{3}{|c|}{ Nestling body mass (g) } & \multicolumn{3}{|c|}{ Nestling tarsus length (mm) } \\
\hline & $F(\mathrm{df})$ & $p$ & Estimate (SE) & $F(\mathrm{df})$ & $p$ & Estimate (SE) \\
\hline Intercept & $3800.31(1,12.7)$ & $<0.001$ & $14.952(0.242)$ & $22,746.15(1,12.8)$ & $<0.001$ & $19.449(0.129)$ \\
\hline Treatment & $0.01(1,12.7)$ & 0.918 & $-0.025(0.242)$ & $0.00(1,12.8)$ & 0.988 & $0.002(0.129)$ \\
\hline Sex & $11.60(1,73.3)$ & 0.001 & $-0.539(0.157)$ & $33.98(1,71.7)$ & $<0.001$ & $-0.406(0.069)$ \\
\hline Treatment $\mathrm{x}$ sex & $3.11(1,73.3)$ & 0.082 & $-0.279(0.157)$ & $7.31(1,71.7)$ & 0.009 & $-0.188(0.069)$ \\
\hline
\end{tabular}

The sum contrasts were applied. $d f$ degrees of freedom, $S E$ standard error 
Fig. 2 Chick tarsus length $($ day +11 post-hatch) in the nests of SRBC-challenged and control (PBS-injected) female great tits, shown by nestling sex. Means (circles) and their confidence intervals (whiskers) estimated from the chick tarsus length model in Table 2 are presented

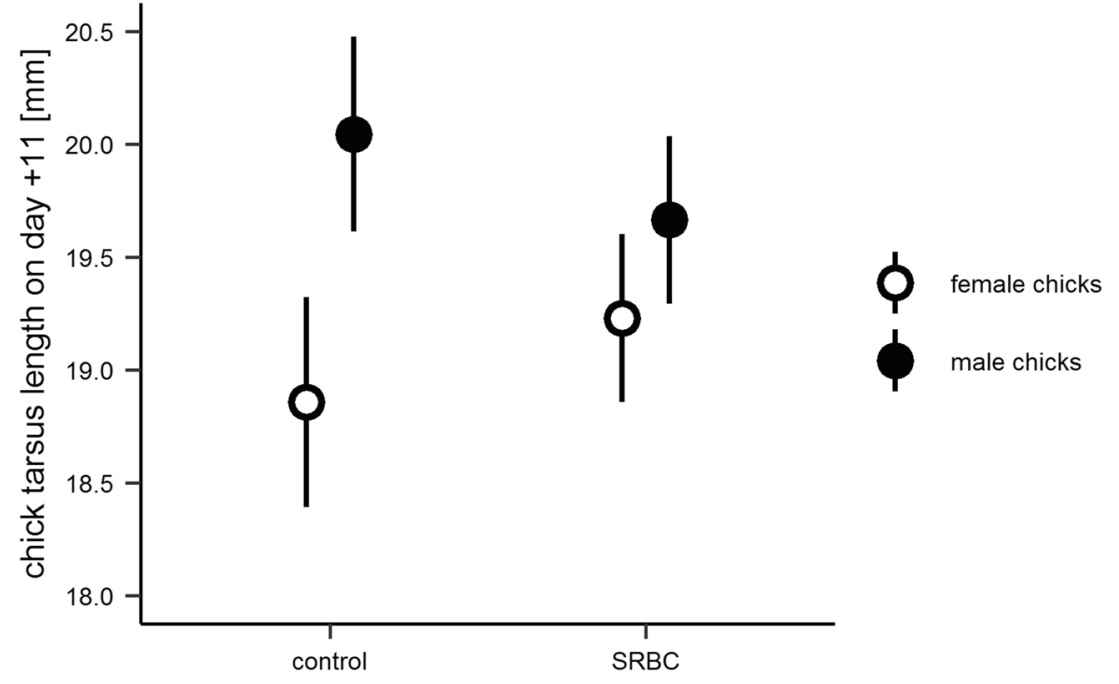

nest was indeed tended only by the female and the model including the outlier showed non-significant results.

\section{Effects of SRBC challenge on offspring body condition and survival}

Some avian studies, for example, on pied flycatchers (Ficedula hypoleuca) and tawny owls (Strix aluco), showed a negative effect of mother immunisation on nestling body mass (Ilmonen et al. 2000; Gasparini et al. 2009). However, others failed to find any effects (Bonneaud et al. 2003; Marzal et al. 2007). The lack of an effect of female immune challenge on nestling body mass in our study may to some extent be explained by the increased mortality of the nestlings of immunised females.

The sex-dependent effect of female SRBC challenge on offspring tarsus length adds to the scarce evidence for sexspecific effects of immunisation of breeding birds on their offspring. To our knowledge, only two studies found such effects. Martyka et al. (2011) demonstrated that female zebra finches (Taeniopygia guttata) injected with SRBC prior and during egg-laying produced larger female but not male offspring. Bowers et al. (2012) observed that female house wrens (Troglodytes aedon) injected with LPS at onset of incubation raised heavier sons and daughters with a stronger immune response to phytohemagglutinin (PHA) in replacement broods. Our result could indicate that the SRBC challenge caused a shift in resource allocation towards female offspring to the disadvantage of male offspring. This could be an adaptive strategy that optimises offspring reproductive value, since great tit males are the more costly sex to raise. Alternatively, parents did not discriminate any of the sexes but on average brought smaller prey items, thus decreasing the volume of food delivered to the nest. If the volume of prey fed to chicks is lower, male offspring, being the more demanding sex during development, will incur a higher cost.
We replicated a negative effect of immune challenge on chick survival in a model passerine and using another, relatively benign antigen. In birds, such effect has been shown only in a few studies. In the study by Bonneaud et al. (2003), LPS-injected females with experimentally enlarged broods had a lower breeding success relative to uninjected females. Higher nestling mortality was also recorded by Ilmonen et al. (2000), who vaccinated female pied flycatchers with the diphtheria-tetanus toxin and by Marzal et al. (2007), who immunised female house martins (Delichon urbica) with the Newcastle disease virus. The drop in nestling survival could have resulted from a change in the size and/or type of prey brought to the nest (Wright et al. 1998; Grzedzicka 2017). In passerines, supply of the largest food items predicts nestling growth and survival (Naef-Daenzer and Keller 1999; Naef-Daenzer et al. 2000; Schwagmeyer and Mock 2008). In addition, as chick mortality was observed only before day +9 , when chicks are brooded by the female (Gosler 1993), immunisation with SRBC could have affected brooding quality.

\section{Conclusion}

We found that female great tits challenged with SRBC, a relatively benign non-pathogenic antigen, incurred costs to their current breeding success. This result indicates a tradeoff between activation of the immune system and reproduction, which supports the costly immunity but not the terminal investment hypothesis. In addition, our findings suggest that such trade-offs can have sex-dependent effects on offspring and could possibly depend on environmental factors that change with hatch dates. This points to the importance of including key ecological and individual correlates in studies on trade-offs between reproduction and immunity. 
Acknowledgements We thank Emilia Grzędzicka, Rafał Martyka and a group of volunteers for their assistance during data collection. Edyta Podmokła helped with molecular sex identification. Anna Dubiec, Tomasz Mazgajski and anonymous referees provided detailed comments on earlier versions of the manuscript.

Authors' contributions Conceptualisation and methodology: Mariusz Cichoń and Justyna Kubacka. Data collection, labwork, analysis and writing: Justyna Kubacka. Review and editing: Mariusz Cichoń and Justyna Kubacka. Funding acquisition, resources and supervision: Mariusz Cichoń

Funding The study was funded by the Institute of Environmental Sciences of the Jagiellonian University. During writing, J.K. was supported by grant no 2016/20/S/NZ8/00434 from the Polish National Science Centre.

Data availability The dataset generated and analysed during the current study is available from the corresponding author on reasonable request.

\section{Compliance with ethical standards}

Conflict of interest The authors declare that they have no conflict of interest.

Ethical approval All applicable Polish and institutional guidelines for the use of animals were followed. The research was performed under a permit from the local ethical committee in Kraków and a ringing permit issued for Justyna Kubacka by the Polish Ringing Centre.

Open Access This article is licensed under a Creative Commons Attribution 4.0 International License, which permits use, sharing, adaptation, distribution and reproduction in any medium or format, as long as you give appropriate credit to the original author(s) and the source, provide a link to the Creative Commons licence, and indicate if changes were made. The images or other third party material in this article are included in the article's Creative Commons licence, unless indicated otherwise in a credit line to the material. If material is not included in the article's Creative Commons licence and your intended use is not permitted by statutory regulation or exceeds the permitted use, you will need to obtain permission directly from the copyright holder. To view a copy of this licence, visit http://creativecommons.org/licenses/by/4.0/.

\section{References}

Ardia DR (2005) Individual quality mediates trade-offs between reproductive effort and immune function in tree swallows. J Anim Ecol 74:517-524. https://doi.org/10.1111/j.1365-2656.2005.00950.x

Barba E, Gil-Delgado JA, Monros JS (1995) The costs of being late: consequences of delaying great tit Parus major first clutches. J Anim Ecol 64:642-651. https://doi.org/10.2307/5806

Bates D, Mächler M, Bolker B, Walker S (2015) Fitting linear mixedeffects models using lme4. J Stat Softw 67:1-48. https://doi.org/10. 18637/jss.v067.i01

Bonneaud C, Mazuc J, Chastel O, Westerdahl H, Sorci G (2004) Terminal investment induced by immune challenge and fitness traits associated with major histocompatibility complex in the house sparrow. Evolution (N Y) 58:2823-2830. https://doi.org/10.1111/j. 0014-3820.2004.tb01633.x
Bonneaud C, Mazuc J, Gonzalez G, Haussy C, Chastel O, Faivre B, Sorci $\mathrm{G}$ (2003) Assessing the cost of mounting an immune response. Am Nat 161:367-379. https://doi.org/10.1086/346134

Both C, Visser ME, Verboven N (1999) Density-dependent recruitment rates in great tits: the importance of being heavier. Proc R Soc B Biol Sci 266:465-469. https://doi.org/10.1098/rspb.1999.0660

Bowers KE, Smith RA, Hodges CJ et al (2012) Sex-biased terminal investment in offspring induced by maternal immune challenge in the house wren (Troglodytes aedon). Proc R Soc B Biol Sci 279: 2891-2898. https://doi.org/10.1098/rspb.2012.0443

Cleasby IR, Nakagawa S, Gillespie DOS, Burke T (2010) The influence of sex and body size on nestling survival and recruitment in the house sparrow. Biol J Linn Soc 101:680-688. https://doi.org/10. 1111/j.1095-8312.2010.01515.x

Clutton-Brock TH (1984) Reproductive effort and terminal investment in iteroparous animals. Am Nat 123:212-229

Colominas-Ciuró R, Santos M, Coria N, Barbosa A (2017) Reproductive effort affects oxidative status and stress in an Antarctic penguin species: an experimental study. PLoS One 12:e0177124. https:// doi.org/10.1371/journal.pone.0177124

Cucco M, Pellegrino I, Malacarne G (2010) Immune challenge affects female condition and egg size in the grey partridge. J Exp Zool A Ecol Genet Physiol 313:597-604. https://doi.org/10.1002/jez.635

Davison F, Kaspers B, Schat KA (2008) Avian Immunology. Elsevier, Oxford, UK

Demas GE, Zysling DA, Beechler BR et al (2011) Beyond phytohaemagglutinin: assessing vertebrate immune function across ecological contexts. J Anim Ecol 80:710-730. https://doi.org/10. 1111/j.1365-2656.2011.01813.x

Eraud C, Duriez O, Chastel O, Faivre B (2005) The energetic cost of humoral immunity in the collared dove, Streptopelia decaocto: is the magnitude sufficient to force energy-based trade-offs? Funct Ecol 19:110-118. https://doi.org/10.1111/j.0269-8463.2005. 00934.x

Eraud C, Jacquet A, Faivre B (2009) Survival cost of an early immune soliciting in nature. Evolution (N Y) 63:1036-1043. https://doi.org/ 10.1111/j.1558-5646.2008.00540.x

Fox J, Weisberg S (2011) An R companion to applied regression, 2nd edn. Sage, Thousand Oaks, CA, USA

Gasparini J, Bize P, Piault R, Wakamatsu K, Blount JD, Ducrest AL, Roulin A (2009) Strength and cost of an induced immune response are associated with a heritable melanin-based colour trait in female tawny owls. J Anim Ecol 78:608-616. https://doi.org/10.1111/j. 1365-2656.2008.01521.x

González-Medina E, Castillo-Guerrero JA, Santiago-Quesada F, Villegas A, Masero JA, Sánchez-Guzmán JM, Fernández G (2015) Regulation of breeding expenditure in the blue-footed booby, Sula nebouxii: an experimental approach. Anim Behav 108:9-16. https:// doi.org/10.1016/j.anbehav.2015.06.025

Gosler A (1993) The great tit. Hamlyn, London, UK

Griffiths R, Double MC, Orr K, Dawson RJG (1998) A DNA test to sex most birds. Mol Ecol 7:1071-1075. https://doi.org/10.1046/j.1365294x.1998.00389.x

Gross WG, Siegel PB, Hall RW et al (1980) Production and persistence of antibodies in chickens to sheep erythrocytes. 2. Resistance to infectious diseases. Poult Sci 59:205-210. https://doi.org/10.3382/ ps.0590205

Grzędzicka E (2017) Immune challenge of female great tits at nests affects provisioning and body conditions of their offspring. Acta Ethol 20:223-233. https://doi.org/10.1007/s10211-017-0265-4

Grzedzicka E (2018) The impact of the female immune challenge on parental feeding rate, mass and body condition index of offspring. Avian Biol Res 11:24-34. https://doi.org/10.3184/ $175815617 X 15106657864820$ 
Hanssen SA (2006) Costs of an immune challenge and terminal investment in a long-lived bird. Ecology 87:2440-2446. https://doi.org/ 10.1890/0012-9658(2006)87[2440:COAICA]2.0.CO;2

Hanssen SA, Hasselquist D, Folstad I, Erikstad KE (2004) Costs of immunity: immune responsiveness reduces survival in a vertebrate. Proc R Soc B Biol Sci 271:925-930. https://doi.org/10.1098/rspb. 2004.2678

Hõrak P, Saks L, Ots I, Kullissaar T, Kollist H, Zilmer M (2003) Physiological effects of immune challenge in captive greenfinches (Carduelis chloris). Can J Zool 81:371-379. https://doi.org/10. 1139/z03-020

Ilmonen P, Hakkarainen et al (1999) Parental effort and blood parasitism in Tengmalm's owl: effects of natural and experimental variation in food abundance. Oikos 86:79-86. https://doi.org/10.2307/3546571

Ilmonen P, Taarna T, Hasselquist D (2000) Experimentally activated immune defence in female pied flycatchers results in reduced breeding success. Proc R Soc B Biol Sci 267:665-670. https://doi.org/10. 1098/rspb.2000.1053

Janeway CA, Travers P, Walport M, Shlomchik M (2001) Immunobiology: the immune system in health and disease, 5th edn. Garland Science, New York, USA

Knowles SCL, Nakagawa S, Sheldon BC (2009) Elevated reproductive effort increases blood parasitaemia and decreases immune function in birds: a meta-regression approach. Funct Ecol 23:405-415. https://doi.org/10.1111/j.1365-2435.2008.01507.x

Lindström J (1999) Early development and fitness in birds and mammals. Trends Ecol Evol 14:343-347. https://doi.org/10.1016/S01695347(99)01639-0

Lozano GA, Ydenberg RC (2002) Transgenerational effects of maternal immune challenge in tree swallows (Tachycineta bicolor). Can J Zool 80:918-925. https://doi.org/10.1139/z02-063

Lüdecke D (2020) sjPlot: data visualization for statistics in social science, $\mathrm{R}$ package version 2.8 .4

Martyka R, Rutkowska J, Cichoń M (2011) Sex-specific effects of maternal immunization on yolk antibody transfer and offspring performance in zebra finches. Biol Lett 7:50-53. https://doi.org/10.1098/ rsbl.2010.0549

Marzal A, Reviriego M, de Lope F, Møller AP (2007) Fitness costs of an immune response in the house martin Delichon urbica. Behav Ecol Sociobiol 61:1573-1580. https://doi.org/10.1007/s00265-0070389-z

Monrós JS, Belda EJ, Barba E (2002) Post-fledging survival of individual great tits: the effect of hatching date and fledging mass. Oikos 99: 481-488. https://doi.org/10.1034/j.1600-0706.2002.11909.x

Naef-Daenzer B, Keller LF (1999) The foraging performance of great and blue tits Parus major and $P$. caeruleus in relation to caterpillar development, and its consequences for nestling growth and fledging weight. J Anim Ecol 68:708-718. https://oi.org/10.1046/j.13652656.1999.00318.x

Naef-Daenzer L, Naef-Daenzer B, Nager RG (2000) Prey selection and foraging performance of breeding great tits Parus major in relation to food availability. J Avian Biol 31:206-214. https://doi.org/10. 1034/j.1600-048X.2000.310212.x

Nager RG, Monaghan P, Griffiths R, Houston DC, Dawson R (1999) Experimental demonstration that offspring sex ratio varies with maternal condition. Proc Natl Acad Sci U S A 96:570-573. https://doi. org/10.1073/pnas.96.2.570

Needham KB, Cook NJ, Rutherford AR, Greives TJ (2017) A prebreeding immune challenge delays reproduction in the female dark-eyed junco Junco hyemalis. J Avian Biol 48:1348-1354. https://doi.org/10.1111/jav.01464

Norris K, Evans MR (2000) Ecological immunology: life-history tradeoffs and immune defence in birds. Behav Ecol 11:19-26. https://doi. org/10.1093/beheco/11.1.19

Ots I, Kerimov AB, Ivankina EV, Ilyina TA, Hõrak P (2001) Immune challenge affects basal metabolic activity in wintering great tits. Proc
R Soc B Biol Sci 268:1175-1181. https://doi.org/10.1098/rspb. 2001.1636

Perrins CM (1970) The timing of birds' breeding seasons. Ibis 112:242255. https://doi.org/10.1111/j.1474-919X.1970.tb00096.x

Perrins CM, McCleery RH (1989) Laying dates and clutch size in the great tit. Wilson Bull 101:236-253

Pinxten R, Eens M, Adriaensen F, Matthysen E, Snoeijs T (2008) The relationship between immunocompetence during winter and subsequent reproductive decisions and survival in the great tit. Anim Biol 58:199-209. https://doi.org/10.1163/157075608X328035

R Core Team (2019) R: a language and environment for statistical computing. Vienna, Austria. https://www.R-project.org/

Råberg L, Nilsson J-Å, Petteri Ilmonen Martinstjernman DH (2000) The cost of an immune response: vaccination reduces parental effort. Ecol Lett 3:382-386. https://doi.org/10.1046/j.1461-0248.2000. 00154.x

Ringsby TH, Saether B-E, Solberg EJ (2007) Factors affecting juvenile survival in house sparrow Passer domesticus. J Avian Biol 29:241247. https://doi.org/10.2307/3677106

Rutkowska J, Martyka R, Arct A, Cichoń M (2012) Offspring survival is negatively related to maternal response to sheep red blood cells in zebra finches. Oecologia 168:355-359. https://doi.org/10.1007/ s00442-011-2115-9

Schielzeth H (2010) Simple means to improve the interpretability of regression coefficients. Methods Ecol Evol 1:103-113. https://doi. org/10.1111/j.2041-210x.2010.00012.x

Schwagmeyer PL, Mock DW (2008) Parental provisioning and offspring fitness: size matters. Anim Behav 75:291-298. https://doi.org/10. 1016/j.anbehav.2007.05.023

Sköld-Chiriac S, Nilsson JÅ, Hasselquist D (2019) Immune challenge induces terminal investment at an early breeding stage in female zebra finches. Behav Ecol 30:166-171. https://doi.org/10.1093/ beheco/ary 147

Snoeijs T, Dauwe T, Pinxten R, Vandesande F, Eens M (2004a) Heavy metal exposure affects the humoral immune response in a free-living small songbird, the great tit (Parus major). Arch Environ Contam Toxicol 46:399-404. https://doi.org/10.1007/s00244-003-2195-6

Snoeijs T, Eens M, van den Steen EVI, Pinxten R (2007) Kinetics of primary antibody responses to sheep red blood cells in birds: a literature review and new data from great tits and European starlings. Anim Biol 57:79-95. https://doi.org/10.1163/ 157075607780002041

Snoeijs T, Van De Casteele T, Adriaensen F et al (2004b) A strong association between immune responsiveness and natal dispersal in a songbird. Proc R Soc B Biol Sci 271:S199-S201. https://doi.org/ 10.1098/rsbl.2003.0148

Stearns SC (1992) The evolution of life histories. Oxford University Press, Oxford

Svensson L (1992) Identification guide to European passerines, 4th edn. British Trust for Ornithology, Norfolk, UK

Trivers RL, Willard DE (1973) Natural selection of parental ability to vary the sex ratio of offspring. Science 179:90-92. https://doi.org/ 10.1126/science.179.4068.90

van Balen JH (1973) A comparative study of the breeding ecology of the great tit (Parus major) in different habitats. Ardea 61:1-93. https:// doi.org/10.5253/arde.v61.p1

Velando A, Drummond H, Torres R (2006) Senescent birds redouble reproductive effort when ill: confirmation of the terminal investment hypothesis. Proc R Soc B Biol Sci 273:1443-1448. https://doi.org/ 10.1098/rspb.2006.3480

Verhulst S, Riedstra B, Wiersma P (2005) Brood size and immunity costs in zebra finches Taeniopygia guttata. J Avian Biol 36:22-30. https:// doi.org/10.1111/j.0908-8857.2005.03342.x

Verhulst S, Tinbergen JM (1991) Experimental evidence for a causal relationship between timing and success of reproduction in the great 
tit Parus m. major. J Anim Ecol 60:269-282. https://doi.org/10. 2307/5459

Verhulst S, van Balen JH, Tinbergen JM (1995) Seasonal decline in reproductive success of the great tit: variation in time or quality? Ecology 76:2392-2403. https://doi.org/10.2307/2265815

Walsh PS, Metzger DA, R H (1991) Chelex 100 as a medium for simple extraction of DNA for PCR-based typing from forensic material. Biotechniques 10:506-513

Wiehn J, Korpimäki E, Pen I (1999) Haematozoan infections in the Eurasian kestrel: effects of fluctuating food supply and experimental manipulation of parental effort. Oikos 84:87-98. https://doi.org/10. $2307 / 3546869$

Williams TD, Christians JK, Aiken JJ, Evanson M (1999) Enhanced immune function does not depress reproductive output. Proc R
Soc B Biol Sci 266:753-757. https://doi.org/10.1098/rspb.1999. 0701

Wright J, Both C, Cotton PA, Bryant D (1998) Quality vs. quantity: energetic and nutritional trade-offs in parental provisioning strategies. J Anim Ecol 67:620-634. https://doi.org/10.1046/j.1365-2656. 1998.00221.x

Zuk M, Stoehr AM (2002) Immune defense and host life history. Am Nat 160(Suppl):S9-S22. https://doi.org/10.1086/342131

Publisher's note Springer Nature remains neutral with regard to jurisdictional claims in published maps and institutional affiliations. 